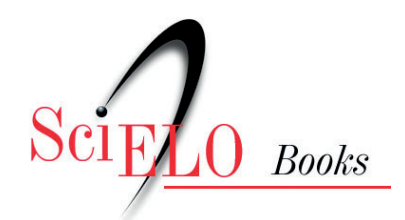

\title{
5. Concepciones y sentidos cotidianos acerca de la lectura y escritura de jóvenes y adultos
}

\author{
María del Carmen Lorenzatti
}

\section{SciELO Books / SciELO Livros / SciELO Libros}

LORENZATTI, M.C., Concepciones y sentidos cotidianos acerca de la lectura y escritura de jóvenes y adultos. In: PAIVA, J., comp. Aprendizados ao longo da vida: sujeitos, políticas e processos educativos [online]. Rio de Janeiro: EDUERJ, 2019, pp. 97-112. Pesquisa em educação/Educação ao longo da vida series. ISBN: 978-65-990364-9-1. https://doi.org/10.7476/9786599036491.0006.

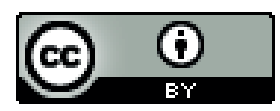

All the contents of this work, except where otherwise noted, is licensed under a Creative Commons Attribution 4.0 International license.

Todo o conteúdo deste trabalho, exceto quando houver ressalva, é publicado sob a licença Creative Commons Atribição $\underline{4.0}$.

Todo el contenido de esta obra, excepto donde se indique lo contrario, está bajo licencia de la licencia Creative Commons Reconocimento 4.0. 


\title{
5 \\ Concepciones y sentidos cotidianos acerca de la lectura y escritura de jóvenes y adultos
}

\author{
María del Carmen Lorenzatti
}

\section{Introducción}

Este artículo abre una buena oportunidad para compartir reflexiones sobre los sentidos cotidianos que los jóvenes y adultos ${ }^{1}$ construyen acerca de la lectura y escritura. La interlocución que podrá propiciar tiene la potencialidad de generar redes de estudio e investigación y eso nos dará mayor posibilidad de otorgar visibilidad a la problemática de la Educación Permanente de Jóvenes y Adultos (EPJA) de América Latina en el mundo.

Cuando hablamos de concepciones y sentidos cotidianos construidos sobre la lectura y escritura desde la alfabetización para jóvenes, adultos y adultos mayores se abre un abanico analítico. Estructuré esta presentación en tres momentos. En primer lugar entiendo que es necesario compartir el abordaje conceptual que

1. En Argentina, se hace referencia sólo a jóvenes y adultos. En nuestro equipo de investigación, Alejandra Vera Calle introduce la discusión de los adultos mayores al campo de la educación de jóvenes y adultos con la intencionalidad de evidenciar un campo de estudios pertinente que se diferencia de la gerontología. 
nos permite analizar y comprender quiénes son los sujetos jóvenes, adultos y desde allí cuáles son las perspectivas teórico-metodológicas que nos orientan en el análisis de la cultura escrita. En un segundo lugar, y a la luz de estas perspectivas, quiero compartir algunos hallazgos de nuestras investigaciones en relación con el sentido que los sujetos jóvenes y adultos le otorgan a la cultura escrita y cómo se posicionan algunas instituciones en torno a la misma con sujetos de nula o baja escolaridad. Finalmente, poner en discusión estos hallazgos con los sentidos que los organismos internacionales y las políticas nacionales le dan a la alfabetización en el marco del aprendizaje a lo largo de toda la vida.

\section{Sujetos y contextos en la EPJA}

Para superar la mirada sobre los jóvenes y adultos desde una cuestión etaria que marca arbitrariamente el paso de una etapa a la otra de la vida de las personas, considero necesario plantear que lo que define el sujeto de la modalidad es la condición social. Desde un abordaje sociológico, Heller (1977) ofrece herramientas teóricas con el concepto de vida cotidiana. Ayuda a comprender que este sujeto (al que Heller denomina particular) necesita aprender a "usar" las cosas, apropiarse de los sistemas de usos y de los sistemas de expectativas para conservarse en una época determinada en el ámbito de un estrato social dado. Esta producción que el hombre necesariamente desarrolla en común con otros hombres y para otros es la forma fenoménica de la genericidad. Esto implica la integración concreta en la que el hombre nace, representada por su "pequeño mundo" (Heller, 1997, p. 27). Es este "pequeño mundo", es la clase o grupo social el espacio generador de sentido en la vida de los sujetos y sus aprendizajes. Es el sujeto (no individual) que se va constituyendo junto a otros, construyendo el sentido de su vida. De este modo se considera al sujeto de la 
EPJA como un sujeto social y concreto. Saleme (1977, p. 96) sostiene la necesidad de comprender a los sujetos reales "sobre cuya cabeza y a buena distancia sobrevuelan discursos internacionales y nacionales" haciendo referencia a las miradas que emergen de diferentes organismos nacionales e internacionales.

También quiero recordar a un maestro uruguayo (Machin, 2015) quien entiende que los sujetos y los contextos son los que le dan especificidad a la EPJA. Nos invita a considerar que se trata de jóvenes y adultos, con sus trayectorias socioeducativas, en contextos de encierro, en zonas rurales, en zonas urbanas, en escuelas, en parroquias. Esto ayuda a comprender cómo se va configurando la práctica a partir de los sujetos que la constituyen y los contextos que la atraviesan. Es esta convergencia particular de sujetos, prácticas y contextos la que es necesario reconocer y analizar para comprender los sentidos que se construyen sobre la lectura y la escritura en la EPJA.

\section{La lectura y escritura como práctica social}

Me interesa realizar un breve recorrido histórico acerca de las perspectivas diversas que analizan la lectura y escritura como práctica social. En primer término, quiero recuperar a Freire (1975), quién desde la antropología filosófica, pone en el centro de la discusión la dimensión política del acto educativo porque entiende que los sujetos no están solos y arrojados en el mundo. Por eso la educación es "acción cultural para la libertad" y "la lectura del mundo precede la lectura de la palabra" y "la escritura como transformación de la realidad objetiva y como escritura de la historia”. Freire (1975) introduce la importancia de considerar el contexto de las acciones de los sujetos. En este marco, el proceso de alfabetización implica dos contextos interrelacionados. Uno de ellos es el de auténtico diálogo entre alumnos y educadores 
(que favorece el proceso de abstracción para analizar la realidad) y otro el contexto real y concreto de los hechos, la realidad social en la cual el hombre existe. Pero no es suficiente esta simple relación, es necesaria una relación de comunicación entre los sujetos. Freire (1975) sostiene además que, desde el punto de vista epistemológico, el conocimiento es algo socialmente constituido y desde el punto de vista histórico, ninguna práctica educativa puede ser comprendida sin referencia al contexto en que ella se da.

Desde los estudios psicogenéticos, Ferreiro y Teberosky (1980) desarrollan una investigación con niños y ponen en jaque la mirada de la enseńanza de la lectura y escritura. En estos estudios emerge la importancia que tiene quien aprende y como se aprende, no como se enseña. Ya no se trata de un problema de métodos (analítico y sintético) y la escritura ya no es una trascripción del lenguaje al papel, sino que es una representación del lenguaje. Es el niño quien construye ese conocimiento en relación con el contexto.

En la década del '80, diversas investigaciones analizan las dimensiones sociales de la cultura escrita (Scribner y Cole, 1981). Desde la perspectiva sociocultural se retoma el concepto de contexto y se lo analiza como parte del proceso de alfabetización a partir de los usos de la cultura escrita en los diferentes contextos. Esta perspectiva ubica los procesos de apropiación en el contexto de la participación en actividades sociales, poniendo énfasis en la construcción del conocimiento mediado por diferentes perspectivas, saberes y prácticas aportadas por los participantes en los eventos de interacción (Roggof, 1999). Desde este enfoque, Kalman (2000, 2003, 2004) desarrolla investigaciones sobre lo que significa aprender a leer y a escribir en una sociedad letrada, cómo los sujetos adultos acceden a conocimientos socialmente validados y usan la lengua escrita para diversos fines, entendiendo la alfabetización como el desarrollo del conocimiento y uso de la lengua escrita en el mundo social y en eventos culturalmente validados. 
En el camino de profundizar esta perspectiva, Street (1984) desarrolla los nuevos estudios de literacidad/letramento. Propone un acercamiento alternativo a partir de la construcción de modelos analíticos, diferenciando entre el modelo autónomo y el modelo ideológico. El primero, analiza la literacidad como una variable independiente del contexto social, una variable autónoma cuyas consecuencias para la sociedad y para la cognición pueden derivarse de su carácter intrínseco (Watt, Goody, Olson, Ong son los investigadores de esta línea). El modelo ideológico analiza estas prácticas como prácticas sociales por su relación con otros aspectos de la vida social, ligadas no sólo a la cultura sino también a las estructuras de poder.

Las investigaciones desarrolladas desde la perspectiva de los Nuevos Estudios de Literacidad (NEL) profundizan el estudio sobre los conocimientos que las personas tienen acerca de las dimensiones sociales de la cultura escrita, sus usos sociales y las consecuencias legales de la misma. La producción en este campo de estudio permite dar cuenta de la complejidad que presenta la problemática de la alfabetización. Literacy (Street, 1993, 2005), literacidad (Zavala, 2002), letramento (Tfouni, 2009) son conceptos orientadores para profundizar sobre los significados que adquiere la cultura escrita en la vida de las personas en contextos sociales más amplios. Se analiza la lectura y escritura como práctica social, se reconocen los saberes que los sujetos tienen en torno a la cultura escrita, sus consecuencias sociales o legales, y se evidencia que toda practica de cultura escrita se produce en el marco de relaciones de poder. Estos estudios implican un abordaje etnográfico ya que es necesario registrar la cotidianeidad de los sujetos en relación con la cultura escrita. 


\section{Sentidos y significaciones otorgadas a la lectura y escritura/ literacidad/letramento}

La perspectiva de los NEL/letramento otorga herramientas conceptuales para analizar los distintos sentidos y significaciones construidas en torno a las prácticas de lectura y escritura por sujetos, instituciones y políticas.

Desarrollé hasta aquí las perspectivas teóricas que permiten comprender los sujetos de la EPJA como sujetos sociales concretos, que desarrollan prácticas en contextos específicos, y tomar distancia de los discursos de las pedagogías dominantes que anclan sus miradas en el "deber ser", vislumbrando siempre la construcción de un sujeto desde la "carencia". Este acercamiento a las prácticas favoreció el análisis de lo que los estudiantes de la EPJA "hacen" con la lectura y escritura. En este sentido me interesa compartir algunos aportes principales de las producciones del equipo de investigación acerca de la lectura y escritura desarrollada en el marco de los NEL.

Señalo que en estos estudios tuvo un lugar importante el trabajo de Kress (2003) quien desde la perspectiva semiótica entiende que hay numerosos recursos modales involucrados en la realización de mensajes (palabras, discursos o escritura; imágenes, música, objetos como modelos tridimensionales). Habla de multimodalidad para referir a los múltiples modos representativos de la realidad y modos de diseminación de esa realidad. En esta línea, la escritura es un modo más. La fertilidad de este concepto radica en comprender de qué manera los sujetos viven, construyen familias, trabajan en el mundo sin hacer uso del código escrito como lo exige o plantea la sociedad y la escuela.

A continuación presento algunas evidencias, resultado de investigaciones desarrolladas en el marco del equipo de investigación. 


\section{Sentidos acerca de letramento/literacidad que construye una seńora de nula escolaridad}

En una mirada sobre diferentes escalas analíticas quiero referirme, en primer lugar, a una seńora de nula escolaridad que, en su cotidianeidad, interactúa con diversos objetos escritos, participa de eventos letrados (Heath, 1983). Son eventos letrados, porque se trata de situaciones donde circulan textos escritos que se enmarcan en instituciones o grupos sociales. Esto también involucra formas de hablar, interactuar, pensar, valorar y creer.

La señora, que se llama Marta Graciela, vive en un ambiente letrado. En su casa pude observar determinados objetos escritos referidos a cuestiones de salud (remedios, prospectos); administrativas (boletas de impuestos); jurídicas (contratos varios); religiosas (Biblia de nińos); familiares (fotos, tarjetas, cartas); laborales (los catálogos de Avon). Frente a cada uno de estos objetos la señora explicita el sentido y los usos de cada uno para diferentes propósitos, mostrando un reconocimiento implícito de las consecuencias de la cultura escrita. Para "sobrevivir la vida", como decía, ella fue desarrollando diversas acciones que involucraron procesos sociales donde está presente la cultura escrita.

Una de esas acciones desplegadas por Marta Graciela es ir a cobrar un subsidio social. La acompañé a realizar ese trámite y pude observar que durante esta actividad desarrolló diferentes gestiones, se relacionó con distintas personas, explicó los propósitos en cada intervención, reconoció e interactuó con diferentes recursos de cultura escrita.

Ella llegó al centro de la ciudad a través del transporte público. En primer lugar, se dirigió al Banco de la Provincia de Córdoba identificando la institución por los colores y el tamaño de los carteles. Debido a que no le pagaron el subsidio en ese Banco se dirigió a otra dependencia estatal, que funciona en el Ministerio de 
Trabajo. Para ello tomó un taxi en el centro de la ciudad y le indicó hacia dónde dirigirse, específicamente le señaló qué camino tomar para dirigirse a la otra institución. Allí le informaron que el pago se hacía en otro banco, el Banco de la Nación Argentina.

En cada uno de estos espacios se relacionó con diferentes personas: cajeras del Banco, taxista, empleados estatales, personas que estaban esperando cobrar. A cada uno de ellos le explicó el problema, en sus diferentes posiciones escucharon y trataron de darle una respuesta.

En estos espacios Marta Graciela interactuó con diversos objetos escritos: transitó entre los carteles que dan cuenta del nombre de las calles de la ciudad, los carteles de los comercios, los carteles de la casilla donde compró los boletos para usar el transporte urbano y aquellos que señalan los Bancos visitados y el Ministerio de Trabajo. En este último lugar, identificó la especificidad de la indicación del ascensor.

También estuvieron presentes artefactos de diseminación de la cultura escrita: las pantallas de las computadoras consultadas por la cajera del Banco y por los empleados del Ministerio, donde ella intentaba mirar la pantalla para conocer lo que sucedía con su pago. Esta actitud de la señora muestra el conocimiento que tiene sobre los circuitos de la información que ella necesitaba en ese momento. En la computadora estaba el registro del recorrido de su pago y el lugar de cobro.

En este trámite volvió a emerger en Marta Graciela el reconocimiento de la importancia de presentar la documentación pertinente: el documento nacional de identidad, la tirilla de comprobante de pago, el recibo de pago donde tuvo que firmar, los números de la espera para cobrar en el Banco Nación. Se puede apreciar que la señora conoce el valor de estos "papelitos" y los archiva en su vivienda porque estos documentos exigidos se constituyen en la llave de entrada para hacer cualquier reclamo. 
Por ejemplo, ella los guarda en una bolsa de nylon para evitar que se pierdan. Esto también se constituye en evidencia de que los documentos van formando a los sujetos como ciudadanos participantes más allá de la firma de su nombre. Es la historia de las relaciones sociales establecidas lo que le van otorgando identidad a la literacidad.

Todos estos recursos e instrumentos de cultura escrita, de las diversas instituciones por donde anduvo Marta Graciela, dan cuenta del conocimiento sobre el valor social de la lengua escrita y cómo se entrecruzan los contextos de las políticas sociales (subsidios específicos) en las prácticas locales.

A partir de lo presentado, es posible identificar que las prácticas de cultura escrita se componen de acciones que responden a propósitos particulares y que los recursos de cultura escrita se inscriben en las relaciones entre instituciones y personas en el marco de relaciones de poder. En este devenir de las prácticas los sujetos van construyendo los sentidos de la cultura escrita en sus vidas.

Es necesario ahora poner la mirada en las condiciones políticas y sociales de las instituciones intervinientes en este trámite y cómo los documentos utilizados exigen que Marta Graciela se relacione con diversas personas involucradas.

\section{Sentidos acerca de letramento/literacidad de las institucio- nes visitadas}

En la investigación, se observó una clara convergencia de instituciones en torno a la cultura escrita en los distintos trámites realizados por Marta Graciela. Sus demandas específicas sobre la escritura se redujeron a la firma de la señora en distintos formularios.

En una de las salidas, ella explica al cajero: 
[...] 'no sé firmar bien pero... ¿Dónde firmo? ... No te vas a reír de mi firma'. Escribió su nombre y la letra de inicio de su apellido: Marta Graciela V. En otra oportunidad expresó: 'Te firmo Vallejos nomás [por solamente]' pero escribió Marta Graciela.

En los distintos momentos observados se identifican procesos de literacidad impuesta (Ivanic y Moss, 2004) por las instituciones oficiales. Solicitan objetos escritos para certificar, acreditar, darles entidad material a las personas que acuden para solicitar algo. Eso vislumbra el ejercicio de poder por parte de las instituciones, otorgan un sentido legal y burocrático a la cultura escrita. Ella se apropia de ese saber: siempre las instituciones demandan papeles que crean obligaciones y acuerdos.

Estos "papelitos que hablan" (Murcia, 2004) dan cuenta de mecanismos de control que las entidades públicas, en este caso, despliegan para controlar y registrar las acciones de los ciudadanos. De esta manera se van conformando archivos de datos personales con los usuarios y/o beneficiarios. Esto no es privativo de las entidades públicas, sucede también con otras instituciones, tales como la iglesia, los sindicatos. Sin embargo, Marta Graciela hace un uso particular de la cultura escrita para defenderse, presionar, demostrar su situación de pobreza.

En esta investigación pude acceder a clases destinadas a los jóvenes y adultos en una institución educativa formal. Allí tuve la oportunidad de observar a Marta Graciela y analicé su relación con la cultura escrita en ese espacio social. Street y Street (2004) hablan de pedagogización de la literacidad y consideran los procesos institucionalizados de enseńanza y aprendizaje en la escuela. En su investigación observaron el distanciamiento entre los sujetos y el lenguaje; los usos metalingüísticos; las maneras en que se le otorga status a la lectoescritura frente al discurso oral como si intrínsecamente fuera superior y por último, los usos del lenguaje 
como si fuera neutral ocultando que se trata de una construcción social. En las clases observadas, la lengua ingresó como disciplina escolar y se mantuvo a cierta distancia de los usos sociales de la lengua escrita que Marta Graciela desarrolla fuera de la escuela. La lengua escrita en la institución escolar adquiere un sentido de "contenido" curricular y pareciera que no se consideran los conocimientos que los sujetos tienen de la misma.

Beinotti y Frasson (2007) también observan procesos de desvinculación del uso social de la lengua y escrita en espacios escolares de nivel primario de jóvenes y adultos. Esto ocurre en el marco de una práctica docente centrada en el coro de silabeo y deletreo, es decir en la lectura de silabas y letras perdiendo el sentido del mensaje. Las investigadoras señalan el uso permanente de la copia del pizarrón al cuaderno, produciendo una especie de homogeneización de las actividades áulicas en el grupo de estudiantes.

Una investigación reciente (Lorenzatti y Arrieta, 2017) muestra los sentidos que se construyen socialmente en torno a la escuela y la enseñanza de la lengua. Un grupo de jóvenes y adultos que asisten a un centro educativo de nivel secundario seńalan que la escuela enseña a "hablar bien" y "escribir correctamente" porque es lo que los estudiantes legitiman como conocimientos válidos aprendidos en la escuela. ¿Qué significa hablar bien y escribir correctamente como contenido escolar?, ¿Cuál es el lugar de la lengua escrita en esta significación? ¿Cuál es el sentido atribuido a "hablar bien"?. En las entrevistas realizadas a jóvenes y adultos de ese grupo se reconoce una modificación en las relaciones de trabajo a partir de poder explicitar sus necesidades en los espacios laborales, con su jefe y con sus compañeros; en la posibilidad de modificar su relación de pareja, o de hablar con la maestra o directora de la escuela de sus hijos, entre otras cuestiones. Una entrevistada expresa que "[...] te vas dando cuenta que tenés cosas para que tu jefe no te pisotee o te maltrate laboralmente" 
y señala que en el espacio curricular Lengua y Comunicación se aprende aspectos relacionados con "[...] la charla y la forma de comunicarte cosas que vos antes no sabías y acá la terminas de aprender" (Entrevista n.1, Noviembre 2013).

Esos decires de los estudiantes se entienden en el marco de lo expresado por profesores y directivos que remarcan constantemente la necesidad de pronunciar correctamente y "de hablar bien”. En los pasillos de la institución, en actos escolares, en el aula se transmiten a modo de "cómo se debe saludar", "qué se debe decir en un trabajo". No lo realizan en un modo despectivo, lo hace con amabilidad y de un modo correctivo relacionado con los requerimientos sociales, del "afuera de la escuela". (Lorenzatti y Arrieta, 2017)

A partir de estas investigaciones, se puede reconocer/evidenciar cómo se construyen socialmente las concepciones y sentidos acerca de la lengua escrita en el marco de los distintos contextos sociales analizados por donde transitan los jóvenes y adultos estudiantes de la EPJA.

\section{Aprendizaje a lo largo de toda la vida}

En esta presentación compartí perspectivas teóricas que orientan el análisis de las prácticas de literacidad de jóvenes y adultos en su vida cotidiana, en distintos espacios sociales. En esa línea, analicé los sentidos y significados otorgados a la literacidad/letramento por una señora de nula escolaridad y por instituciones donde transita realizando trámites. No pretendo con esto generalizar el análisis, pero si plantear que la señora no es analfabeta sino letrada, que vive en contextos letrados, que interactúa con objetos escritos y conoce las consecuencias legales y sociales de la cultura escrita. 
Las políticas específicas tendientes a promover el acceso a los procesos de literacidad y escolarización en la modalidad de jóvenes y adultos se reducen a la implementación de planes y campañas de alfabetización. Estas propuestas, en su mayoría, no están integradas y articuladas a otros proyectos globales, y en este sentido, es que se atomiza el abordaje de la problemática del acceso a la cultura escrita. Se recorta la mirada a la decodificación del fonema en grafema sin considerar los contextos de uso de la lengua escrita. Diferentes investigaciones (Beinotti y Frasson, 2007; Bowman, 2008; Arrieta, 2015) muestran que los sujetos jóvenes y adultos que ingresan a la escuela encuentran otro modo de relacionarse con la lengua, un modo fragmentado que estimula una escritura sin sentido en los cuadernos.

Me gustaría cerrar esta presentación con una reflexión sobre la convocatoria del Coloquio que generó el artículo y lo que implica pensar el aprendizaje a lo largo de la vida en el campo de la educación de jóvenes y adultos y la educación popular.

Entiendo que este postulado de Unesco interpela a los gobiernos, en tanto son responsables de generar oportunidades de aprendizaje. Esto no se remite sólo a la escolaridad obligatoria sino también en los posibles trayectos formativos por fuera del ámbito formal del sistema educativo. En ese marco señalo la importancia de explorar los aprendizajes realizados en diferentes espacios sociales y la necesidad de generar mecanismos, procedimientos y/o estrategias para que sean reconocidos.

También nos interpela a nosotros investigadores comprometidos con este campo socioeducativo. Tengo más preguntas que respuestas frente a la complejidad de la educación de jóvenes y adultos. Algunas de ellas se resumen de la siguiente manera: 
¿Cómo pensar en abordajes curriculares específicos para la población joven y adulta incorporando los aprendizajes realizados? ¿Cómo sostener y promover procesos de formación docente específica, que rompa los modelos de enseñanza de nińos y provea de herramientas conceptuales para definir propuestas para jóvenes y adultos? ¿De qué manera se fortalecen los procesos de confianza en si mismos/as frente al conocimiento en sujetos estigmatizados por ausencia de escolaridad en su infancia? ¿Cómo trabajar con instancias de políticas locales o regionales para incidir en la incorporación de esta problemática en la agenda de discusión nacional o regional?

Son algunas de las preguntas que nos demandan como investigadores para constituir redes entre los equipos, construir conocimiento y compartir con colegas de América Latina los debates, las discusiones y los hallazgos de nuestras investigaciones.

\section{Referências}

ARRIETA, Rocío. "Entonces ponemos dos puntos, comillas, mayúscula y todos estamos contentos”. Un análisis de los usos sociales de la escritura escolar en jóvenes y adultos de la ciudad de Córdoba. Ponencia presentada en las XII Jornadas Regionales de Investigación en Humanidades y Ciencias Sociales. Facultad de Humanidades y Ciencias Sociales de la Universidad Nacional de Jujuy. Argentina, 2015.

BEINOTTI, Gloria e FRASSON, Marta. Oralidad y escritura en las aulas de adultos. Córdoba: Universidad Nacional de Córdoba, 2007.

BOWMAN, María Alejandra. El maestro como mediador en procesos de alfabetización (tese). Universidad Nacional de Córdoba, Córdoba, 2008.

FERREIRO, Emilia e TEBEROSKY, Ana. Los sistemas de escritura en el desarrollo del niño. México: Siglo XXI Editores, 1980.

FREIRE, Paulo. Acción cultural para la libertad. Buenos Aires: Tierra Nueva, 1975.

HEATH, Shirley Brice. "What no bedtime story means: narrative skills at home and school". Language in Society, v. 11, 1983, pp. 49-72. 
HELLER, Agnes. Sociología de la vida cotidiana. Barcelona: Ediciones Península, 1977.

IVANIC, Roz e MOSS, Wendy. "La incorporación de las prácticas de escritura de la comunidad en la educación”. In NIÑO-MURCIA, Mercedes et al (eds.). Escritura y Sociedad. Nuevas perspectivas teóricas y etnográficas. Lima, Perú: Red para el Desarrollo de las Ciencias Sociales en el Perú, 2004.

KALMAN, Judith. "¿Somos lectores o no? Una revisión histórica del concepto de alfabetización y sus consecuencias". In Antología Lecturas para la Educación de Adultos. México: Editorial Limusa S. A. de C. V. Grupo Noriega Editores, 2000. (Vol. III Programas del INEA, p. 496).

KALMAN, Judith. Escribir en la plaza. México: Fondo de Cultura Económica, 2003.

- Saber lo que es la letra. Una experiencia de lectoescritura con mujeres de Mixquic. México: Biblioteca para la actualización del maestro. Siglo XXI Editores, 2004.

KRESS, Ghunter. Literacy in the New Media Age. London: Routledge, 2003.

LORENZATTI, Maria del Carmen. Contextos, sujetos y procesos en escuelas de jóvenes y adultos [CD]: VII Congreso Argentino de Antropología Social. Córdoba, Argentina, 2004.

LORENZATTI, María del Carmen e ARRIETA, Rocío. "La escuela de jóvenes y adultos: un espacio para aprender 'la charla' y la 'buena escritura'”. In FREITAS, Antonio Francisco Ribeiro de et al (orgs.). Os sentidos da formação em rede: observaçôes sobre as práticas de leitura e das práticas dos leitores. Maceió: Edufal, 2017, pp. 139-50.

MACHIN, Felipe. "La educación de adultos en Uruguay y la formación de educadores". In LORENZATTI María del Carmen e LIGORRIA, Verónica (comp.). Educación de jóvenes y adultos y educación rural. Aportes para la formación de futuros maestros. pp. 14-25. Universidad Río Cuarto: Unirio Ed. Disponível em: https://www.unrc.edu.ar/unrc/comunicacion/editorial/repositorio/978-987-688-151-7.pdf. Acesso em 20 nov. 2017.

ROGOFF, Bárbara. Aprendices del Pensamiento. El desarrollo cognitivo en el contexto social. Buenos Aires: Editorial Paidós, 1999.

SALEME, María de Burnichon. Decires. Córdoba, Argentina: Vaca Narvaja Editor, 1997. 
II2 Aprendizados ao longo da vida

SCRIBNER, Sylvia e COLE, Michael. The psichology of literacy. Cambridge: Harvard University Press, 1981.

STREET, Brian. Literacy and theory practice. Cambridge: Cambridge University Press, 1984.

. Cross-Cultural Approaches to Literacy. Cambridge University Press, 1993.

. "Recent applications of New Literacy Studies in Educational Contexts". Research in the Teaching of English, vol. 39, n. 4, 2005, pp. 417-23.

STREET, Joanna C. e STREET, Brian V. La escolarización de la literacidad. In NIÑO-MURCIA, Mercedes et al (ed.). Escritura y Sociedad. Nuevas perspectivas teóricas y etnográficas. Lima, Perú: Red para el Desarrollo de las Ciencias Sociales en el Perú, 2004, pp. 181-210.

TFOUNI, Leda Verdiani. “A escrita: remédio ou veneno?” In AZEVEDO, Maria Amélia e MARQUES, Maria Lúcia (orgs.). Alfabetização hoje. São Paulo: Cortez, 2009.

ZAVALA, Virginia. (Des)encuentros con la escritura: escuela y comunidad en los Andes peruanos. Lima, Perú: Red para el Desarrollo de las Ciencias Sociales en el Perú, 2002. 